\title{
Transcatheter aortic valve replacement- management of patients with significant coronary artery disease undergoing aortic valve interventions: surgical compared to catheter-based approaches in hybrid procedures
}

Hardy Baumbach ${ }^{1 *}$, Eva R. Schairer ${ }^{1}$, Kristina Wachter ${ }^{2}$, Christian Rustenbach $^{1,3}$, Samir Ahad ${ }^{1}$, Alina Stan ${ }^{1}$, Stephan Hill ${ }^{2}$, Peter Bramlage ${ }^{4}$ (D) Ulrich F. W. Franke ${ }^{1}$ and Tim Schäufele ${ }^{2}$

\begin{abstract}
Background: Coronary artery disease (CAD) is associated with poorer outcomes after aortic valve replacement (AVR). For high-risk patients with complex CAD, combined transcatheter aortic valve replacement (TAVR) plus offpump/minimally-invasive coronary artery bypass (OPCAB/MIDCAB) has been proposed.

Methods: A prospective registry analysis was performed to compare the characteristics and outcomes of patients undergoing TAVR+OP/MIDCAB with those undergoing TAVR plus percutaneous coronary intervention (PCI) and surgical AVR plus coronary artery bypass grafting (CABG) between 2008 and 2015 at a single site in Germany.

Results: 464 patients underwent SAVR+CABG, 50 underwent TAVR+OP/MIDCAB, and 112 underwent TAVR+PCI. The mean ages $(p<0.001)$ and logistic EuroSCOREs $(p<0.001)$ were similarly higher in TAVR+OP/MIDCAB and $T A V R+P C l$ patients compared to SAVR+CABG patients. Prior cardiac surgery was more common in TAVR+PCI than in TAVR+OP/MIDCAB and SAVR+CABG patients $(p<0.001)$. Procedural times were shortest $(p<0.001)$, creatine kinase (muscle brain) levels least elevated $(p<0.001)$, pericardial tamponade least common $(p=0.027)$, and length of hospital stay shortest $(p=0.011)$ in TAVR+PCl, followed by TAVR+OP/MIDCAB and SAVR+CABG patients. In-hospital mortality was highest for TAVR+OP/MIDCAB patients (18.0\%) with comparable rates for TAVR+PCI and SAVR+CABG groups (9.0 and 6.9\%; $p=0.009$ ). Mortality by 12 months was more probable after TAVR+OP/MIDCAB (HR: 2.17, $p=0.002)$ and TAVR/PCI (HR: 1.63, $p=0.010)$ than after SAVR+CABG, with the same true of rehospitalisation (HR: 2.39, $p=0.003$ and HR: 1.63, $p=0.033$ ).

Conclusions: TAVR+OP/MIDCAB patients share many characteristics with TAVR+PCI patients, with only slightly poorer long-term outcomes. In patients ineligible for SAVR+CABG and TAVR+PCl, hybrid interventions are reasonable second-line options.
\end{abstract}

Keywords: Aortic stenosis, Coronary artery disease, Aortic valve replacement, Off-pump coronary artery bypass, Percutaneous coronary intervention

\footnotetext{
* Correspondence: hardy.baumbach@rbk.de

'Department of Cardiovascular Surgery, Robert Bosch Hospital, Auerbachstr.

110, 70376 Stuttgart, Germany

Full list of author information is available at the end of the article
}

(c) The Author(s). 2019 Open Access This article is distributed under the terms of the Creative Commons Attribution 4.0 International License (http://creativecommons.org/licenses/by/4.0/), which permits unrestricted use, distribution, and reproduction in any medium, provided you give appropriate credit to the original author(s) and the source, provide a link to the Creative Commons license, and indicate if changes were made. The Creative Commons Public Domain Dedication waiver (http://creativecommons.org/publicdomain/zero/1.0/) applies to the data made available in this article, unless otherwise stated. 


\section{Background}

An estimated $40-75 \%$ of the severe aortic stenosis (AS) patients who undergo transcatheter aortic valve replacement (TAVR) have concomitant coronary artery disease (CAD) [1]. In patients with a primary indication for surgical aortic valve replacement (SAVR), a history of coronary artery bypass grafting (CABG) increases operative risk; to diminish this effect, guidelines recommend combination of both procedures into one hybrid operation [2]. For patients ineligible for SAVR, TAVR plus coronary revascularisation hybrids have now been suggested. Besides reducing the number of surgeries a patient must endure, revascularisation just prior to TAVR also minimises the risk of coronary ischaemia during rapid ventricular pacing, to which the hypertrophied myocardium is particularly vulnerable .

A number of studies have suggested the comparable safety and efficacy of TAVR plus PCI to that of isolated TAVR $[3,4]$. Guidelines now tentatively recommend this combination for severe AS patients with concomitant coronary stenosis occupying $>70 \%$ of the artery diameter [2]; however not all coronary lesions are treatable with PCI. More recently, off-pump CABG (OPCAB) has been proposed as a method of complete coronary revascularisation in patients with complex stenosis and/or high SYNTAX scores [5, 6], with the off-pump technique avoiding the harmful effects of cardiopulmonarybypass (CPB) [7]. OРCAB has been used to treat multi-vessel disease requiring a larger operative area, with a recent 4-patient series outlining its successful use immediately prior to transaortic (TAo) TAVR [8]. A modified version of OPCAB, known as minimally invasive direct $C A B G$ (MIDCAB), has been developed for the treatment of single-vessel disease, achievable through a smaller incision. Since the first documented MIDCAB plus transapical (TA) TAVR hybrid in 2010 [9], several other successful cases have been reported $[5,10]$. However, only one larger study has evaluated the safety and feasibility of TAVR+OPCAB/MIDCAB to date [11], and no comparisons with TAVR+PCI and SAVR+CABG have been performed.

The aim of the present study was to compare the characteristics and outcomes of patients undergoing TAVR $+\mathrm{OP} / \mathrm{MIDCAB}$ with those undergoing TAVR+PCI, with data for those undergoing SAVR+CABG included as a benchmark control. This information will add to the currently limited pool of evidence for each TAVR hybrid.

\section{Methods}

The present prospective, observational single-center study was carried in Germany between January 2008 and October 2015. Elderly patients with severe AS and concomitant extensive CAD who had a primary indication for aortic valve replacement were consecutively enrolled.
The study received prior approval from the "Ärztekammer Stuttgart" institutional review board and was carried out in accordance with the declaration of Helsinki. All patients provided their written informed consent.

\section{Inclusion/exclusion criteria}

Severe AS patients with a primary indication (without contraindications) for AVR at our site were included. Those who elected not to undergo one of these procedures; who underwent concomitant procedures other than CABG, OPCAB, MIDCAB and PCI; or who had sclerosis rather than stenosis of coronary vessels were excluded. Other exclusion criteria included the iatrogenic suturing of a coronary ostium and the fact that the date of PCI was not within 12 months before TAVR. Eligible patients were divided into three groups depending upon hybrid intervention type (SAVR+CABG; TAVR $+\mathrm{OPCAB}$ or TAVR+MIDCAB [TAVR+OP/MIDCAB]; and TAVR+PCI).

\section{Choice of surgical vs. transcatheter aortic valve replacement}

SAVR was the preferred AVR procedure, unless the patient was deemed ineligible by an interdisciplinary Heart Team based on factors such as a high surgical risk score, advanced age, relevant comorbidities, and short life expectancy. Such patients were evaluated for TAVR eligibility, with access route determined by a careful assessment of patient anatomy considered alongside the preferred coronary revascularisation approach (see below).

\section{Choice of coronary revascularisation approach}

CAD complexity was evaluated in all patients with a primary indication for SAVR or TAVR, and those with an intermediate/high Synergy between PCI with Taxus and Cardiac Surgery (SYNTAX) score [12] were indicated for concomitant revascularisation. For patients scheduled to undergo SAVR, CABG through open surgery was the preferred revascularisation technique. For those scheduled for TAVR, the mode of revascularisation was determined by thorough assessment of the number and complexity of diseased coronary vessels. Unless considered unsuitable due to left anterior descending artery (LAD) proximal lesions or an extremely high SYNTAX score, patients preferentially underwent PCI, with the TAVR access route determined by the Heart Team. In the case of single-vessel LAD or left circumflex artery disease, MIDCAB via a left antero-lateral minithoracotomy followed by TA-TAVR was preferred. In the case of multi-vessel complex disease, OPCAB via a median sternotomy followed by TAo-TAVR was preferred. 


\section{Definitions}

Pulmonary disease was defined as COPD with or without medication. CKD was defined as to $\mathrm{KDIGO/KDOQI}$ and considered compensated when CKD stabilizes on Stage III. Prior cardiac surgery included any surgical valve replacement or reconstruction or $C A B G$ or any other surgical intervention at the thoracic aorta. A history of myocardial infarction (MI) was considered present if MI had occurred within the last 90 days. A history of stroke/TIA was considered as an event happened during lifetime which is severely affecting day-to-day functioning. Hospitalisation during follow-up was divided into early ( $<3$ months after intervention) and late (> 3 months after intervention) hospitalisation and was defined as any event which lead to a hospital stay.

\section{Statistical analysis}

Continuous variables are presented as means \pm standard deviations (SD) or medians and interquartile ranges (IQR) and categorical variables as absolute numbers and frequencies (\%). ANOVA, Kruskal-Wallis tests were used for comparisons across the three study groups, with t-test and Wilcoxon- Mann-Whitney-test used to compare the two TAVR groups only, where appropriate. Freedom from death and rehospitalisation were estimated using Kaplan-Meier analysis and a log-rank test. Cox proportional hazard coefficients and $p$-values (adjusted for age, EuroSCORE, left ventricular ejection fraction [LVEF], New York Heart Association [NYHA] class, pulmonary disease (asthma bronchiale, lung cancer, pulmonary fibrosis), pulmonary hypertension, arrhythmias, chronic kidney disease [CKD], aortic insufficiency, and mitral/tricuspid valve disease) were calculated for each of the TAVR hybrids. Effective orifice area (EOA), body mass index (BMI) and mean aortic valve (AV) gradient were not adjusted for, owing to a high number of missing values. All analyses were carried out using SPSS version 24.0 (IBM Corporation, Armonk, NY, USA), with $p$-values of $<0.05$ considered significant.

\section{Results}

Of the 718 patients initially enrolled, concomitant coronary revascularisation and aortic valve replacement was performed in 626 cases (87.2\%) (Fig. 1). Of these, 464 patients $(74.1 \%)$ underwent SAVR+CABG, $50(8.0 \%)$ underwent TAVR+OP/MIDCAB as hybrid procedures (for details see below), and 112 (17.9\%) underwent TAVR+PCI. Of the 50 patients undergoing TAVR+OP/MIDCAB 24 patients underwent OPCAB and 26 MIDCAB.

\section{Patient characteristics}

The mean ages of TAVR+OP/MIDCAB and TAVR+PCI patients were similar, both being higher than in the SAVR + CABG group (82.1 and 81.3 vs. 78.7 years; $p<0.001$ ) (Table 1). The same trend was evident for the prevalence of pulmonary hypertension, compensated CKD, prior dialysis, and tricuspid valve disorders, as well as mean logistic EuroSCORE (36.4 and 36.1 vs. 21.0; $\mathrm{p}<0.001$ ). NYHA class III/IV was most common in the TAVR+PCI group, followed by the TAVR+OP/MIDCAB and SAVR+CABG groups $(\mathrm{p}<0.001)$, with the same trend seen for

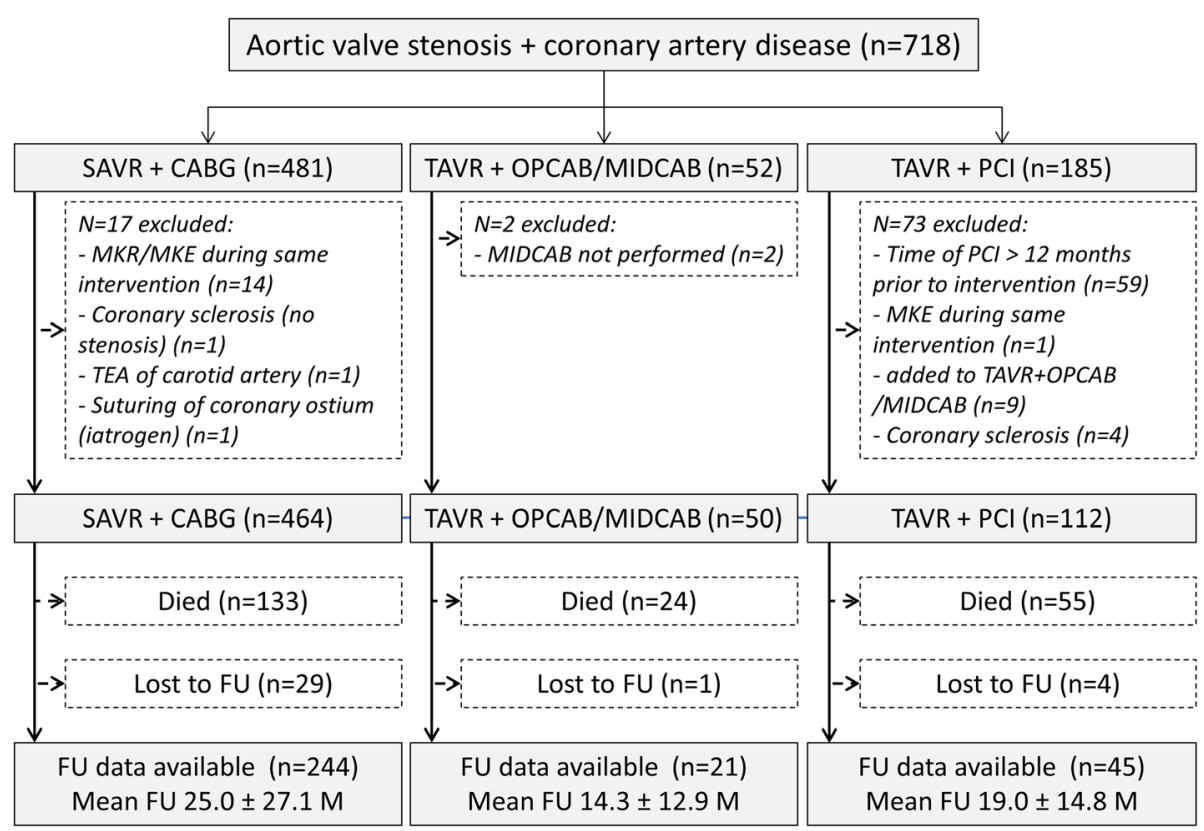

Fig. 1 Patient flow 
Table 1 Baseline patient characteristics

\begin{tabular}{|c|c|c|c|c|}
\hline & $S A V R+C A B G$ & TAVR + OP/MIDCAB & TAVR + PCl & $p$-value \\
\hline & $(n=464)$ & $(n=50)$ & $(n=112)$ & \\
\hline & $\begin{array}{l}\text { mean } \pm S D \text { or median }(I Q R) \\
\text { or } n(\%)\end{array}$ & $\begin{array}{l}\text { mean } \pm S D \text { or median }(I Q R) \\
\text { or } n(\%)\end{array}$ & $\begin{array}{l}\text { mean } \pm S D \text { or median }(I Q R) \\
\text { or } n(\%)\end{array}$ & \\
\hline Age (years) & $78.7 \pm 3.1$ & $82.1 \pm 4.3$ & $81.3 \pm 5.7$ & $<0.001$ \\
\hline Female gender & $168(36.2)$ & $19(38.0)$ & $39(34.8)$ & 0.923 \\
\hline BMI $\left(\mathrm{kg} / \mathrm{m}^{2}\right)$ & $26.2 \pm 3.8$ & $26.1 \pm 4.7$ & $26.0 \pm 3.9$ & 0.011 \\
\hline Clinical history & & & & \\
\hline History of stroke/TIA & $46(9.9)$ & $7(14.0)$ & $16(14.3)$ & 0.675 \\
\hline History of Ml (<90 days) & $138(29.8)$ & $28(56.0)$ & $79(70.5)$ & 0.318 \\
\hline Previous cardiac surgery & $21(4.5)$ & $1(2.0)$ & $38(33.9)$ & $<0.001$ \\
\hline Diabetes mellitus & $180(38.8)$ & $19(38.0)$ & $33(29.5)$ & 0.318 \\
\hline Hypertension & $454(98.1)$ & $50(100.0)$ & $109(97.3)$ & 0.516 \\
\hline Pulmonary disease & $56(12.1)$ & $9(18.0)$ & $27(24.1)$ & 0.020 \\
\hline Pulmonary hypertension ${ }^{a}$ & $128(27.6)$ & $27(54.0)$ & $62(55.4)$ & $<0.001$ \\
\hline Chronic kidney disease & & & & \\
\hline Compensated & $115(24.8)$ & $22(44.0)$ & 49 (43.8) & $<0.001$ \\
\hline Prior dialysis & $8(1.7)$ & $3(6.0)$ & $7(6.3)$ & 0.014 \\
\hline Other valve disorders & & & & \\
\hline Mitral & $235(50.6)$ & $32(64.0)$ & $86(76.8)$ & $<0.001$ \\
\hline Tricuspid & $17(3.7)$ & $6(12.0)$ & $12(10.7)$ & $<0.001$ \\
\hline EuroSCORE I (\%) & $21.0 \pm 17.5$ & $36.4 \pm 22.4$ & $36.1 \pm 18.9$ & $<0.001$ \\
\hline NYHA class & & & & $<0.001$ \\
\hline$|/| \mid$ & $206(44.4)$ & $8(16.0)$ & $10(8.9)$ & \\
\hline III/IV & $258(55.6)$ & $42(84.0)$ & $102(91.1)$ & \\
\hline Multi-vessel CAD & $359(77.4)$ & $42(84.0)$ & $83(74.1)$ & 0.570 \\
\hline AV parameters & & & & \\
\hline LVEF (\%) & $55.7 \pm 13.8$ & $48.3 \pm 14.4$ & $51.3 \pm 2.6$ & $<0.001$ \\
\hline $\mathrm{EOA}\left(\mathrm{cm}^{2}\right)$ & $0.8 \pm 0.3$ & $0.7 \pm 0.2$ & $0.7 \pm 0.2$ & $<0.001$ \\
\hline Mean AV gradient (mmHg) & $40.7 \pm 17.1$ & $40.4 \pm 14.0$ & $42.5 \pm 15.2$ & 0.027 \\
\hline Peak AV gradient (mmHg) & $66.6 \pm 25.7$ & $67.9 \pm 19.7$ & $72.2 \pm 23.3$ & 0.150 \\
\hline Annulus size $\left(\mathrm{cm}^{2}\right)$ & $22.9 \pm 4.2$ & $23.7 \pm 2.2$ & $22.9 \pm 2.4$ & 0.092 \\
\hline
\end{tabular}

Legend: ${ }^{\text {a PapSys }}>30 \mathrm{mmHg}$

pulmonary and mitral valve disease. Prior cardiac surgery was much more common in the TAVR+PCI compared to TAVR+OP/MIDCAB and SAVR+CABG groups (33.9\% vs. 2.0 and $4.5 \% ; p<0.001)$. TAVR+PCI and TAVR+OP/MID$\mathrm{CAB}$ patients had comparable mean EOAs and LVEFs, significantly lower compared to SAVR+CABG patients. The mean AV gradient was slightly higher in the TAVR $+\mathrm{PCI}$ than in the TAVR+OP/MIDCAB and SAVR + CABG groups.

\section{Peri-procedural details}

The TA route was most commonly used in both the TAVR+PCI (62.5\%) and TAVR+OP/MIDCAP (58.0\%) patients (Table 2). However, while the majority of the remaining TAVR+PCI patients underwent TF-TAVR (36.6\%; $p<0.001$ ), all of the remaining TAVR+OP/MID$\mathrm{CAB}$ patients underwent TAo-TAVR.

Every patient in the TAVR+PCI group underwent two separate procedures (PCI first, TAVR as a second procedure, however not more than 12 months later). Every patient in the TAVR+OP/MIDCAB- group had their intervention in one procedure.

The median procedural duration was shortest for TAVR + PCI patients, followed by TAVR+OP/MIDCAB and SAVR+CABG patients $(67,175$, and $221 \mathrm{~min} ; \mathrm{p}<0.001)$. The lowest number of erythrocyte packs were used in the TAVR+PCI, followed by the SAVR+CABG and TAVR $+\mathrm{OP} / \mathrm{MIDCAB}$ groups $(p=0.001)$. 
Table 2 Peri-procedural details and hospital stay

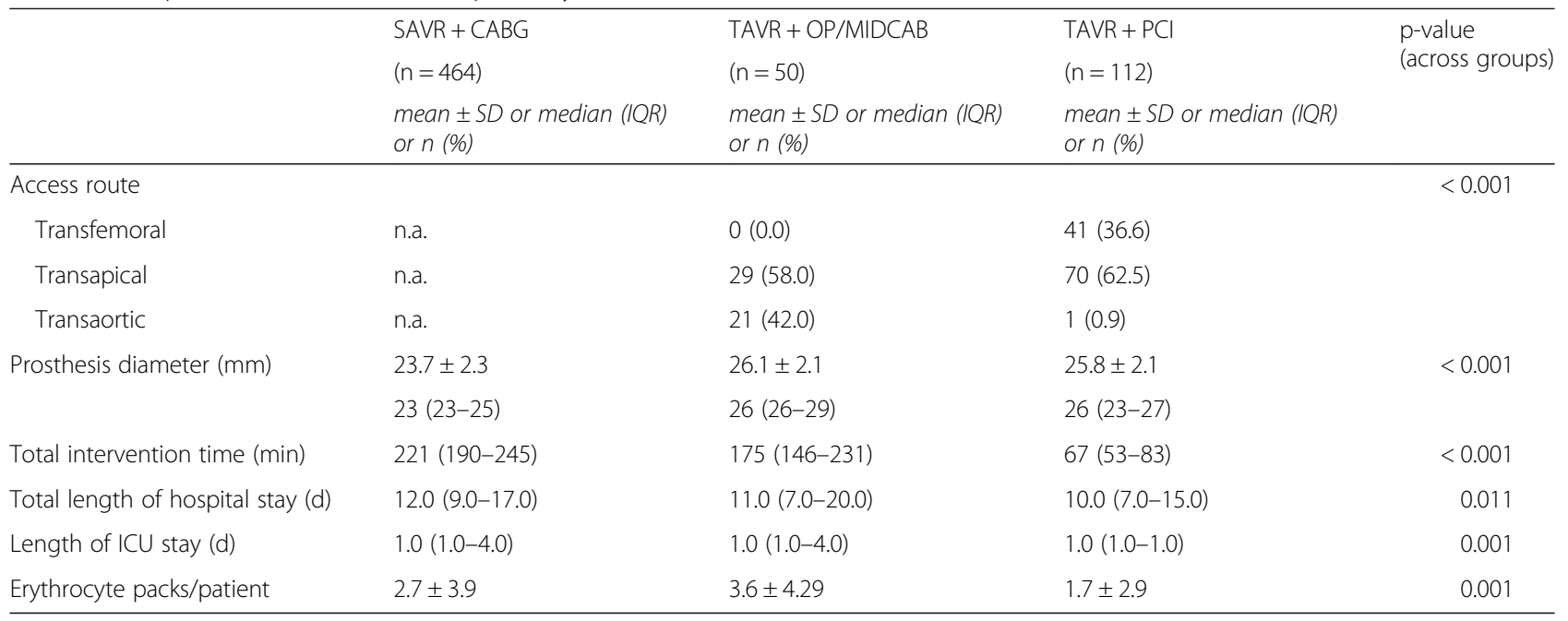

\section{Complications}

Conversion to open surgery was necessary in three TAVR+PCI patients (2.7\%: all due to grade III aortic insufficiency) and two TAVR+OP/MIDCAB patients (4.0\%: one due to intraoperative prosthesis dislocation and one due to resuscitation) (Table 3). Most cases of re-thoracotomy became necessary due to tamponade or bleeding complications. No case is known where a re-thoracotomy had to be performed because of bypass or stent insufficiency. Only one peri-procedural death occurred (TAVR+PCI patient with grade III aortic insufficiency) because of ventricular rupture. The rates of intra-operative (within $72 \mathrm{~h}$ ) stroke/TIA and MI were low and not significantly different across groups; however, creatine kinase (muscle brain type [CK-MB]) levels were least elevated in TAVR+PCI patients, followed by

Table 3 Peri-procedural and post-operative complications

\begin{tabular}{|c|c|c|c|c|}
\hline & $\begin{array}{l}\text { SAVR + CABG } \\
(n=464)\end{array}$ & $\begin{array}{l}\text { TAVR + OP/MIDCAB } \\
(n=50)\end{array}$ & $\begin{array}{l}\text { TAVR }+\mathrm{PCl} \\
(\mathrm{n}=112)\end{array}$ & $\begin{array}{l}\text { p-value } \\
\text { (across groups) }\end{array}$ \\
\hline & $\begin{array}{l}\text { mean } \pm S D \text { or median }(I Q R) \\
\text { or } n(\%)\end{array}$ & $\begin{array}{l}\text { mean } \pm S D \text { or median }(I Q R) \\
\text { or } n(\%)\end{array}$ & $\begin{array}{l}\text { mean } \pm S D \text { or median }(I Q R) \\
\text { or } n(\%)\end{array}$ & \\
\hline Intra-operative mortality & $0(0.0)$ & $0(0.0)$ & $1(0.9)$ & 0.009 \\
\hline Intra-operative resuscitation & $2(0.4)$ & $2(4.0)$ & $3(2.7)$ & 0.017 \\
\hline Myocardial infarction & $2(0.4)$ & $1(2.0)$ & $0(0.0)$ & 0.225 \\
\hline CK-MB (U/I) & $51.1 \pm 57.1$ & $47.2 \pm 81.8$ & $31.1 \pm 35.0$ & $<0.001$ \\
\hline Stroke/TIA & $23(5.0)$ & $1(2.0)$ & $5(4.5)$ & 0.622 \\
\hline Conversion to open surgery ${ }^{a}$ & n.a. & $2(4.0)^{b}$ & $3(2.7)^{c}$ & 0.017 \\
\hline Re-thoracotomy & $36(7.8)$ & $5(10.0)$ & $3(2.7)$ & 0.117 \\
\hline Pericardial tamponade & $31(6.7)$ & $1(2.0)$ & $1(0.9)$ & 0.027 \\
\hline AKI stage $\|/\| \|$ & $48(10.3)$ & $5(10.0)$ & $11(9.8)$ & 0.984 \\
\hline Post-op. resuscitation (30d) & $34(7.3)$ & $5(10.0)$ & $6(5.4)$ & 0.557 \\
\hline Post-operative dialysis (30d) & $39(8.4)$ & $5(10.0)$ & $14(12.5)$ & 0.190 \\
\hline Permanent & $5(1.1)$ & $2(4.0)$ & $5(4.5)$ & 0.028 \\
\hline Post-operative AF (30d) & $41(8.8)$ & $3(6.0)$ & $4(3.6)$ & 0.154 \\
\hline Post-operative PPI (30d) & $25(5.4)$ & $1(2.0)$ & $11(9.9)$ & 0.091 \\
\hline In-hospital mortality & $32(6.9)$ & $9(18.0)$ & $9(9.0)$ & 0.009 \\
\hline 30d overall mortality & $34(7.4)$ & $8(16.0)$ & $7(6.3)$ & 0.077 \\
\hline
\end{tabular}

Legend: ${ }^{\mathrm{a} C o n v e r s i o n}$ to open surgery was defined as sternotomy and change to SAVR with a heart-lung-machine, ${ }^{\mathrm{b}}$ one patient experienced intraoperative dislocation of the prosthesis, the second patient was resuscitated; call due to severe aortic regurgitation, one patient died as a result 
TAVR+OP/MIDCAB and SAVR+CABG groups $(31.1 \pm$ 35.0, $47.2 \pm 81.8$ and $51.1 \pm 57.1 \mathrm{U} / \mathrm{l} ; p<0.001$ ). The rate of pericardial tamponade followed a similar trend (0.9, 2.0 and $6.7 \% ; p=0.027$ ). Conversely, intra-operative resuscitation was required in only $0.4 \%$ of SAVR+CABG patients, compared to 2.7 and $4.0 \%$ of TAVR+PCI and TAVR+OP/MIDCAB patients, respectively $(p=0.017)$.

Post-operatively, a smaller proportion of SAVR+CABG patients required permanent dialysis compared to TAVR $+\mathrm{OP} / \mathrm{MIDCAB}$ and TAVR+PCI patients $(1.1 \%$ vs. 4.0 and $4.5 \% ; p=0.028)$. In-hospital mortality was highest for TAVR+OP/MIDCAB patients with rates comparable between TAVR+PCI and SAVR+CABG patients $(18.0 \%$ vs. 9.0 and $6.9 \% ; p=0.009)$. Of the 9 patients $(18 \%)$ in the TAVR+OP/MIDCAB group who died in hospital, 4 died from acute circulatory collapse with cardiogenic shock, 2 due to multi organ failure following acute myocardial infarction and 3 patients died due to no cardiac cause. In the TAVR+PCI group 9 (9\%) died, 3 of them due to acute circulatory collapse with cardiogenic shock, 1 patient suffered a ventricular rupture and another patient a stroke following multi organ failure. 4 patients died due to no cardiac cause.

No patient undergoing the TAVR+MIDCAB procedure underwent additional PCI of a right-sided target vessel following the index procedure.

\section{Hospital stay}

The total length of stay in hospital following the intervention was shortest for patients who underwent TAVR $+\mathrm{PCI}$, followed by TAVR+OP/MIDCAB and SAVR +CABG (10.0 [7.0-15.0], 11.0 [7.0-20.0], and 12.0 [9.017.0] days; $p=0.011$ ) (Table 2). During this time, a median of one day was spent in ICU for all groups.

\section{Follow-up}

Follow-up data were available for $45 \mathrm{TAVR}+\mathrm{PCI}$ patients (40.2\%), 21 TAVR+OP/MIDCAB patients (42\%) and 247 SAVR+CABG patients (53.2\%). Mean follow-up times were $19.0 \pm 14.8$ months, $14.3 \pm 12.9$ months, and $25.0 \pm$ 27.1 months, respectively.

At 12 months, survival rate was poorest in the TACI+OP/MIDCAB (65.5\%), followed by the TAVR + PCI (71.1\%) and SAVR+CABG (86.7\%; log-rank test: $p<0.001$ ) group (Fig. 2a). The same was true of rehospitalisation $(53.6,69.0$, and $86.6 \%$, respectively; log-rank test: $\mathrm{p}<0.001$ ) (Fig. 2b). Adjusted Cox hazard regression revealed that the likelihood of mortality by 12 months was higher in patients undergoing TAVR+OP/MIDCAB (HR: 2.17; 95\% CI: 6.98-43.02; $p=0.002)$ and TAVR/PCI (HR: 1.63 , 95\% CI: $13.36-$ $56.66 ; p=0.010)$ procedures. A similar trend was observed for any rehospitalisation outcome (HR: 2.39,
95\% CI: 19.84-34.46; $p=0.003$ and HR: $1.63,95 \%$ CI: $23.40-88.62 ; p=0.033$, respectively).

\section{Hybrid procedures}

Of the 50 patients that underwent a hybrid procedure, 24 underwent TAVR+OPCAB and 26 TAVI+MIDCAB. Although these groups were very small compared to the principal comparison groups, we explored these further in Additional file 1: Table S1 and Additional file 2 Table S2, as well as in Additional file 3: Figure S1 and Additional file 4: Figure S2.

\section{Discussion}

While the characteristics of patients undergoing TAVR $+\mathrm{OP} / \mathrm{MIDCAB}$ and TAVR+PCI were fairly similar, those with a history of cardiac surgery appeared more likely to be managed with TAVR+PCI. Both TAVR hybrids resulted in less myocardial injury, less pericardial tamponade, shorter procedural durations, and shorter hospital stays compared to SAVR+CABG, with these advantages particularly marked for TAVR+PCI. While both TAVR hybrids were associated with a greater need for intra-operative resuscitation and permanent dialysis, as well as a decreased likelihood of survival and freedom from rehospitalisation at 12 months compared to SAVR + CABG, these outcomes were not vastly dissimilar between the two TAVR groups.

\section{Complications}

All three hybrid procedures had excellent peri-procedural safety, with low and comparable rates of intra-operative death, stroke/TIA and MI across groups. However, CK-MB, a marker of myocardial injury, was significantly less elevated in patients undergoing TAVR hybrids compared to SAVR+CABG. A greater rise in CK-MB levels has been associated with increased cardiovascular mortality and poorer clinical outcomes [13]. This highlights the importance of this finding, which is supported by a previous study of isolated aortic valve replacement procedures that observed a smaller rise in markers of cardiac injury after TAVR compared to SAVR [14]. This benefit may be explained by the avoidance of CPB in TAVR hybrids. Furthermore, procedural duration, a known predictor of post-TAVR myocardial injury [15], was longer in the TAVR+OP/MIDCAB than TAVR+PCI group and may explain the lower CK-MB levels in the latter patients. Nevertheless, for patients with complex CAD in whom TAVR $+\mathrm{PCI}$ is not feasible, use of TAVR+OP/MIDCAB appears to result in an acceptable degree of myocardial injury, with length of surgery expected to decrease with experience.

Pericardial tamponade was much less common in the TAVR hybrid groups than in the SAVR+CABG group, likely reflecting the shorter, less invasive procedures requiring a lesser degree of heart manipulation. Indeed, 


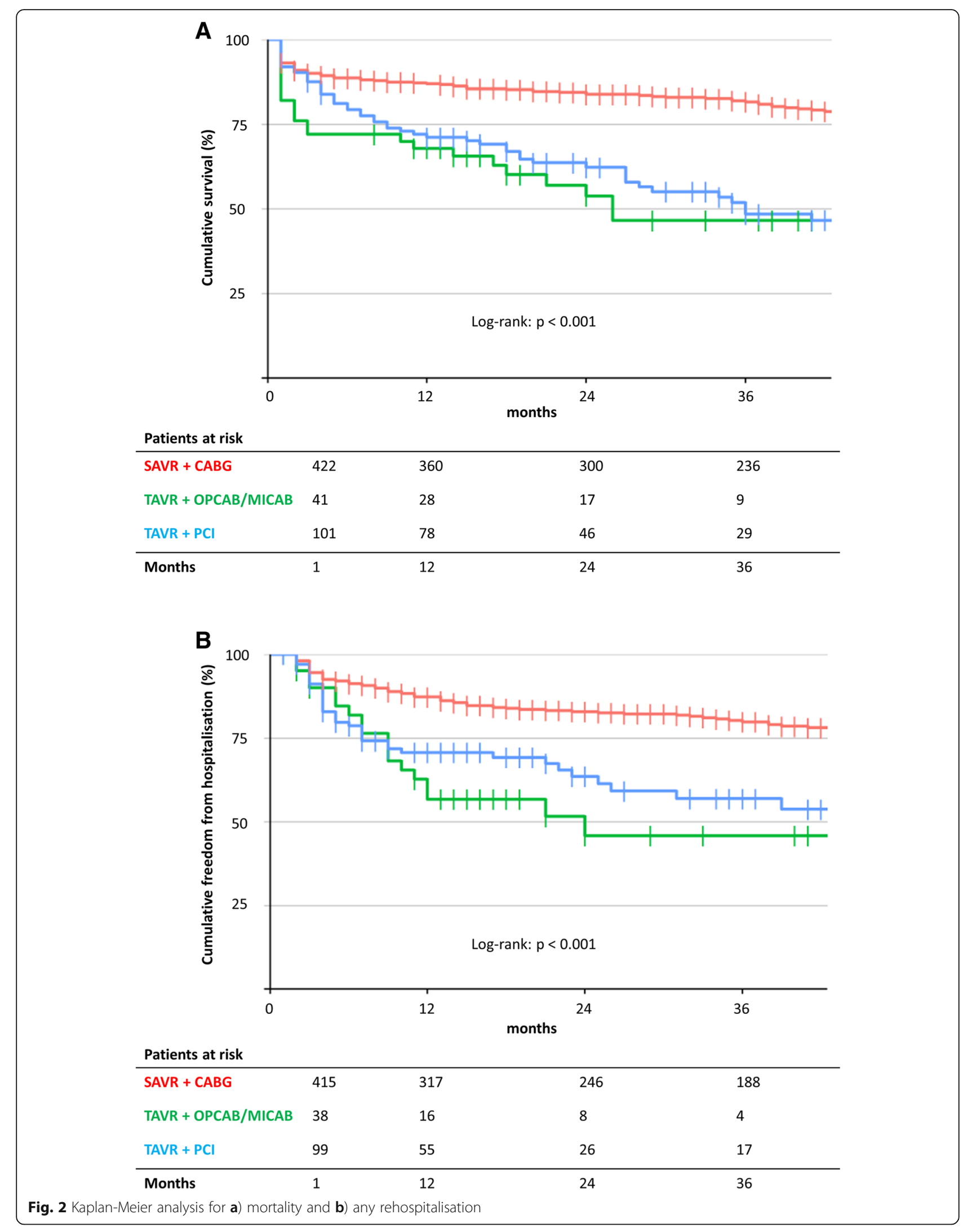


prolonged intervention time has been identified as a risk factor for pericardial effusion during cardiac surgery [16]. The same logic may be applied to the lower rate of pericardial tamponade in the TAVR+PCI compared to TAVR+OP/MIDCAB patients. The high number of patients with prior cardiac surgery in the TAVR+PCI group may also have relevance here, given that previous cardiac operations have been associated with a lower risk of effusion [16]. Conversion to open surgery was required in a slightly smaller proportion of TAVR+PCI patients compared to TAVR+OP/MIDCAB patients. The reason for this is unclear, though is more likely to be related to TAVR access route rather than to revascularisation technique, given that the reasons for conversion were mainly TAVR complications.

The rate of in-hospital mortality (18\%) was particularly high for TAVR+OP/MIDCAB patients. This is likely a combination of their significantly higher surgical risk (EuroSCORE 36.4\%), disease burden, and age compared to the SAVR+CABG group, and the fact that the procedure was more invasive and involved compared to TAVR + PCI. Indeed, a mortality rate of $18.8 \%$ has been reported for patients with a EuroSCORE of 33.8\% undergoing isolated TAVR involving a mini-thoracotomy [17], which is similar to that of the current composite procedure. Another possible contributor is learning curve, given that the TAVR+OP/MIDCAB hybrid is relatively new and infrequently performed, particularly in the case of MIDCAB. Thus, poorer survival rates are to be expected. However, when compared to the $14.3 \%$ 30-day mortality rate previously reported for this particular hybrid procedure in a comparable patient population [11], the rate in the present study is still particularly elevated. The reason for this remains unclear, but is likely related to patient factors.

\section{Length of procedure and hospital stay}

Due to different degrees of invasiveness, shorter procedural times are a known advantage of TAVR (particularly TF-TAVR) compared to SAVR [18], of PCI compared to OP/MIDCAB, and of MIDCAP compared to CABG [19]. It is therefore unsurprising that TAVR+PCI was the shortest procedure, followed by TAVR+OP/MIDCAB and SAVR+CABG, with the number of erythrocyte packs required following this trend. Furthermore, despite their higher risk profile, patients undergoing TAVR hybrids had shorter hospital stays than those who underwent SAVR+CABG, further indicating the potential for less invasive surgery to reduce resource utilisation. Indeed, reduced bed costs after TAVR have been identified as a major driver of its cost-effectiveness relative to SAVR [20]. Considering that an advantage of minimally-invasive surgery is its facility to allow earlier discharge, it is surprising that the length of hospital stay for TAVR+PCI patients was only moderately shorter than that for TAVR+OP/MIDCAB patients, despite nearly $40 \%$ of the former group undergoing the procedure via a purely percutaneous approach. However, this may be explained by the fact that baseline EuroSCORE and NYHA class, two factors identified as predictive for length of hospital stay after TAVR in clinical practice [18], were fairly comparable between TAVR groups. The ubiquitous use of general anaesthesia, despite PCI and TF-TAVR being feasible under conscious sedation, may also have contributed [21]. Nevertheless, there appears to be scope for further exploitation of early discharge after fully percutaneous hybrid procedures.

\section{Long-term survival and rehospitalisation}

Long-term survival was poorer in both TAVR groups compared to the SAVR+CABG group. While risk factors such as a more advanced age, higher NYHA class, lower LVEF and a greater number of comorbidities were more prevalent in TAVR groups [22], a higher risk of mortality remained after adjustment for these and other possible confounding factors, the same being true of rehospitalisation. Thus, SAVR+CABG is likely to remain the gold standard in patients who are eligible. Though both the probability of death and rehospitalisation by 12 months were elevated to a greater degree in patients who underwent TAVR+OP/MIDCAB than in those who underwent $\mathrm{TAVR}+\mathrm{PCI}$, the differences were relatively small. Thus, $\mathrm{TAVR}+\mathrm{OP} / \mathrm{MIDCAB}$ may be considered a reasonable approach in patients who are ineligible for both SAVR + CABG and TAVR+PCI. Long-term direct comparisons between patients who undergo the hybrid procedure, those who undergo the two procedures separately, those who undergo one procedure only, and those who elect not to undergo either procedure would be interesting, but would require an extremely large dataset.

\section{Limitations}

The main limitation of the present study was the lack of randomisation, resulting in different patient populations with varying $\mathrm{n}$-numbers. However, this represents the real-world use of the different interventions, with TAVR reserved for higher-risk patients and OP/MIDCAB reserved for those in whom PCI is not feasible. A further limitation was the combination of TAVR+OPCAB and TAVR+MIDCAB patients into one group, considering that the procedures have important differences. However, small patient numbers prevented separate comparisons. As the procedures become more diffuse, larger comparative studies will be possible. Finally, follow-up data was available for only a small proportion of the study population; thus, comparisons regarding long-term mortality and rehospitalisation are severely limited and should be interpreted with caution. 


\section{Conclusions}

Patients undergoing TAVR+OP/MIDCAB share many characteristics with those undergoing TAVR+PCI. Both TAVR hybrids appear to result in shorter procedural durations, less complications and shorter length of hospital stay but mortality and rehospitalisation at 12 months are increased. Thus, in patients ineligible for $\mathrm{SAVR}+\mathrm{CABG}$ and TAVR+PCI, hybrid interventions may be reasonable second-line options, especially if at high surgical risk and complex CAD.

\section{Additional files}

Additional file 1: Table S1. Baseline patient characteristics TAVR+OP vs. MIDCAB. (DOCX $21 \mathrm{~kb})$

Additional file 2: Table S2. Peri-procedural details, hospital stay and complications TAVR+OP vs. MIDCAB (DOCX $20 \mathrm{~kb}$ )

Additional file 3: Figure S1. Patient flow TAVR+OP VS. MIDCAB (TIF $528 \mathrm{~kb}$ )

Additional file 4: Figure S2. Kaplan-Meier analysis for A) mortality and B) any rehospitalisation TAVR+OP vs. MIDCAB. (ZIP $461 \mathrm{~kb})$

\section{Abbreviations}

ABR: Aortic valve replacement; AV: Aortic valve; BMl: Body mass index CABG: Coronary artery bypass grafting; CAD: Coronary artery disease; CKD: Chronic kidney disease; CPB: CardioPulmonary-bypass; EOA: Effective orifice area; LAD: Left anterior descending; LVEF: Left ventricular ejection fraction; MIDCAB: Minimally-invasive coronary artery bypass; NYHA: New York heart association; OPCAB: Off-pump coronary artery bypass; PCI: Percutaneous coronary intervention; SAVR: Surgical aortic valve replacement; SYNTAX: Synergy between PCI with Taxus and cardiac surgery; TA: Transapical; TAO: Transaortic; TAVR: Transcatheter aortic valve replacement

\section{Acknowledgements}

None.

\section{Funding}

No funding was obtained.

\section{Availability of data and materials}

Available from the first author upon reasonable request.

\section{Authors' contributions}

Made substantial contributions to conception and design, or acquisition of data (HB, ERS, KW, CR, SA, AS, SH, UFWF, TS). Made substantial contributions to the analysis and interpretation of data (HB, ERS, KW, CR, SA, AS, SH, PB, UFWF, TS). Were involved in drafting the manuscript (HB, ERS, PB) or revising it critically for important intellectual content (KW, CR, SA, AS, SH, UFWF, TS). Given final approval of the version to be published (All). Agreed to be accountable for all aspects of the work (All).

\section{Ethics approval and consent to participate}

The study received prior approval from the "Ärztekammer Stuttgart" institutional review board and was carried out in accordance with the declaration of Helsinki. All patients provided their written informed consent.

\section{Consent for publication}

Not applicable.

\section{Competing interests}

$\mathrm{HB}$ and $\mathrm{PB}$ are working as consultant physicians for Edwards Lifesciences. HB, SA and UF are working as consultant physicians for JenaValve Technology $\mathrm{GmbH}$. HB received institutional grants from JenaValve Technology $\mathrm{GmbH}$ and Edwards Lifesciences. PB received institutional grants from Edwards Lifesciences. The other authors have no competing interest to disclose.

\section{Publisher's Note}

Springer Nature remains neutral with regard to jurisdictional claims in published maps and institutional affiliations.

\section{Author details}

${ }^{1}$ Department of Cardiovascular Surgery, Robert Bosch Hospital, Auerbachstr. 110, 70376 Stuttgart, Germany. ${ }^{2}$ Department of Cardiology, Robert Bosch Hospital, Stuttgart, Germany. ${ }^{3}$ Cardiothoracic Surgery, Heartcenter University Hospital Cologne, Cologne, Germany. ${ }^{4}$ Institute for Pharmacology and Preventive Medicine, Cloppenburg, Germany.

Received: 9 August 2018 Accepted: 22 April 2019

Published online: 14 May 2019

References

1. Goel SS, Ige M, Tuzcu EM, Ellis SG, Stewart WJ, Svensson LG, Lytle BW, Kapadia SR. Severe aortic stenosis and coronary artery disease--implications for management in the transcatheter aortic valve replacement era: a comprehensive review. J Am Coll Cardiol. 2013:62(1):1-10.

2. Kolh P, Windecker S, Alfonso F, Collet JP, Cremer J, Falk V, Filippatos G, Hamm C, Head SJ, Juni P, et al. 2014 ESC/EACTS guidelines on myocardial revascularization: the task force on myocardial revascularization of the European Society of Cardiology (ESC) and the European Association for Cardio-Thoracic Surgery (EACTS). Developed with the special contribution of the European Association of Percutaneous Cardiovascular Interventions (EAPCI). Eur J Cardiothorac Surg. 2014;46(4):517-92.

3. Wenaweser P, Pilgrim T, Guerios E, Stortecky S, Huber C, Khattab AA, Kadner A, Buellesfeld L, Gloekler S, Meier B, et al. Impact of coronary artery disease and percutaneous coronary intervention on outcomes in patients with severe aortic stenosis undergoing transcatheter aortic valve implantation. Eurolntervention. 2011;7(5):541-8

4. Abdel-Wahab M, Mostafa AE, Geist V, Stocker B, Gordian K, Merten C, Richardt D, Toelg R, Richardt G. Comparison of outcomes in patients having isolated transcatheter aortic valve implantation versus combined with preprocedural percutaneous coronary intervention. Am J Cardiol. 2012; 109(4):581-6.

5. Kobayashi J, Shimahara Y, Fujita T, Kanzaki H, Amaki M, Hata H, Kume Y, Yamashita K, Okada A. Early results of simultaneous Transaortic Transcatheter aortic valve implantation and Total arterial off-pump coronary artery revascularization in high-risk patients. Circ J. 2016;80(9):1946-50.

6. Manoly I, Hasan R, Brazier A, Farooq V, Thompson T, Karunaratne D, Naylor $H$, Fraser D. Feasibility of hybrid off pump artery bypass grafting and transaortic transcatheter aortic valve implantation: A case series. Catheter Cardiovasc Interv. 2017;89(7):1273-1279. https://doi.org/10.1002/ccd.26610. Epub 2016 Jul 12.

7. Djedovic S, Mujanovic E, Djedovic M, Rajkovic S, Jahic M, Tosic Z. Surgical revascularization in elderly patients with and without cardiopulmonary bypass. Med Arch. 2013;67(5):351-3.

8. Baumbach H, Ahad S, Hill S, Schaufele T, Adili S, Wachter K, Franke UF Transaortic Transcatheter aortic valve implantation and concomitant off pump revascularization. Innovations (Phila). 2016;11(5):363-6.

9. Cheung A, Hon JK, Ye J, Webb J. Combined off-pump transapical transcatheter aortic valve implantation and minimally invasive direct coronary artery bypass. J Card Surg. 2010;25(6):660-2.

10. Ahad S, Baumbach H, Hill S, Franke UF. Transapical aortic valve implantation and minimally invasive off-pump bypass surgery. Interact Cardiovasc Thorac Surg. 2014;18(2):248-9.

11. Ahad S, Wachter K, Rustenbach C, Stan A, Hill S, Schaufele T, Ursulescu A, Franke UF, Baumbach $\mathrm{H}$. Concomitant therapy: off-pump coronary revascularization and transcatheter aortic valve implantation. Interact Cardiovasc Thorac Surg. 2017;25(1):12-7.

12. Kim YH, Park DW, Kim WJ, Lee JY, Yun SC, Kang SJ, Lee SW, Lee CW, Park SW, Park SJ. Validation of SYNTAX (synergy between PCI with Taxus and cardiac surgery) score for prediction of outcomes after unprotected left main coronary revascularization. JACC Cardiovasc Interv. 2010;3(6):612-23.

13. Paradis J-M, Maniar HS, Lasala JM, Kodali S, Williams M, Lindman BR, Damiano RJ, Moon MR, Makkar RR, Thourani VH, et al. Clinical and functional outcomes associated with myocardial injury after Transfemoral and 
Transapical TAVR: A sub-analysis from the PARTNER trial. JACC Cardiovasc Interv. 2015;8(11):1468-79.

14. Parenica J, Nemec P, Tomandl J, Ondrasek J, Pavkova-Goldbergova M, Tretina M, Jarkovsky J, Littnerova S, Poloczek M, Pokorny P, Spinar J, Cermakova Z, Miklik R, Malik P, Pes O, Lipkova J, Tomandlova M, Kala P. Prognostic utility of biomarkers in predicting of one-year outcomes in patients with aortic stenosis treated with transcatheter or surgical aortic valve implantation. PLoS One. 2012;7(12):e48851. https://doi.org/10.1371/ journal.pone.0048851.

15. Yong ZY, Wiegerinck EMA, Boerlage-van Dijk K, Koch KT, Vis MM, Bouma BJ, Henriques JPS, Cocchieri R, Piek JJ, de Mol BAJM, et al. Predictors and prognostic value of myocardial injury during Transcatheter aortic valve implantation. Circulation. 2012;5(3):415-23.

16. Ashikhmina E, Schaff HV, Sinak L, Li Z, Dearani JA, Suri RM, Park SJ, Orszulak TA, Sundt TM 3rd: Pericardial effusion after cardiac surgery: risk factors, Patient Profiles, and Contemporary Management Ann Thorac Surg 89; 2010.

17. Lefèvre $T$, Kappetein $A P$, Wolner $E$, Nataf $P$, Thomas $M$, Schächinger $V$, De Bruyne B, Eltchaninoff $H$, Thielmann M, Himbert D, et al. One year follow-up of the multi-Centre European PARTNER transcatheter heart valve study. Eur Heart J. 2011;32(2):148-57.

18. Reinöhl J, Kaier K, Gutmann A, Sorg S, von zur Mühlen C, Siepe M, Baumbach H, Moser M, Geibel A, Zirlik A, et al. In-hospital resource utilization in surgical and transcatheter aortic valve replacement. BMC Cardiovasc Disord. 2015;15(1):132.

19. Yang M, Xiao L-B, Gao Z-S, Zhou J-W. Clinical effect and prognosis of offpump minimally invasive direct coronary artery bypass. Med Sci Monit. 2017;23:1123-8

20. Fairbairn TA, Meads DM, Hulme C, Mather AN, Plein S, Blackman DJ, Greenwood JP. The cost-effectiveness of transcatheter aortic valve implantation versus surgical aortic valve replacement in patients with severe aortic stenosis at high operative risk. Heart. 2013;99(13):914-20.

21. Arbel Y, Zivkovic N, Mehta D, Radhakrishnan S, Fremes SE, Rezaei E, Cheema AN, Al-Nasser S, Finkelstein A, Wijeysundera HC. Factors associated with length of stay following trans-catheter aortic valve replacement - a multicenter study. BMC Cardiovasc Disord. 2017;17(1):137.

22. Di Eusanio M, Fortuna D, De Palma R, Dell'Amore A, Lamarra M, Contini GA, Gherli T, Gabbieri D, Ghidoni I, Cristell D, et al. Aortic valve replacement: results and predictors of mortality from a contemporary series of 2256 patients. J Thorac Cardiovasc Surg. 2011;141(4):940-7.

Ready to submit your research? Choose BMC and benefit from:

- fast, convenient online submission

- thorough peer review by experienced researchers in your field

- rapid publication on acceptance

- support for research data, including large and complex data types

- gold Open Access which fosters wider collaboration and increased citations

- maximum visibility for your research: over $100 \mathrm{M}$ website views per year

At $\mathrm{BMC}$, research is always in progress.

Learn more biomedcentral.com/submissions 